\title{
Cytotoxic activity of ethanolic extracts of Eleutherococcus species cultivated in Poland on HL60 leukemia cell line
}

\author{
Daniel Zaluski ${ }^{1 \star}$, Helena Danuta Smolarz ${ }^{2}$, Anna Bogucka-Kocka²
}

${ }^{1}$ Chair and Department of Pharmacognosy, Jagiellonian University, Collegium Medicum, Medyczna 9, 30-568 Cracow, Poland

${ }^{2}$ Chair and Department of Pharmaceutical Botany, Medical University of Lublin, Chodzki 1, 20-093 Lublin, Poland

\begin{tabular}{l}
\hline ARTICLE INFO \\
\hline Received 09 December 2013 \\
Accepted 10 January 2014 \\
\hline
\end{tabular}

\section{Keywords:}

Eleutherococcus,

eleutherosides,

HL60,

cytotoxicity,

apoptosis.

\begin{abstract}
The Eleutherococcus species including 40 species native to Asia are medicinal plants widely used in traditional medicine. Some of these species are cultivated at the botanical gardens in Europe. On the basis on our earlier studies it was concluded that the extracts of analyzed species act as antioxidants, inhibitors of MMPs, and cytotoxic against Jurkat 45 leukemia cell line. In this study, the anti-leukemic potential of roots and leaves from six Eleutherococcus species cultivated in Poland was determined.

The in vitro cytotoxic activity towards human promyelotic leukemia cell line HL60 using trypan blue assay was evaluated. The induction of apoptosis in stimulated leukemia cells was determined by AnnexinV method. Morphological changes in treated cells were observed by microscopic investigations.

The results showed that ethanolic extracts from the roots and the leaves of E. senticosus, E. setchuensis, E. sessiliflorus, E.gracilistylus, E. henryi and E. divaricatus exhibit cytotoxic effect towards leukemic HL60 cells. The received IC50 values for roots ranged from 49$208 \mu \mathrm{g} / \mathrm{mL}$ and for the leaves from 116-518 $\mu \mathrm{g} / \mathrm{mL}$. The ethanol extract from the roots of $E$. divaricatus showed the highest cytotoxic and proapoptotic effect on HL60 human lymphoid leukemia cell line.
\end{abstract}

\section{INTRODUCTION}

Medicinal plants are the ingredients of many currently important pharmaceutical drugs with broad biological activity. There has been a growing interest in studying plant secondary metabolites as they represent a tremendous library of potentially useful leading compounds for new drug development. In fact, many modern drugs are compounds isolated from plants, which are used in the treatment of many diseases including cancer, e.g. taxol from yew tree, or vincristine from periwinkle. Pharmaceutical industry is still searching for new drugs with anticancer potency. Since there are no effective drugs to treat most cancers, it seems a good solution to produce the anti-leukemic drugs with natural origin. Some natural products are mostly composed of complex compounds, which act synergistically $[5,10]$.

Eleutherococcus is a genus of the Araliaceae family, which includes approximately 40 species native to North Russia and Asia. The plants from Eleutherococcus genus

\footnotetext{
Corresponding author

* e-mail: daniel.zaluski@uj.edu.pl

tel./fax: +48 127423702
}

have been used in medicine, especially in Chinese medicine for many years. The roots of Eleutherococcus senticosus have been traditionally used as a folk remedy for many diseases including diabetes, hypertension and cancer. The leaves are used as a tonic, as a functional beverage commercially marketed for reducing liver damage and accelerating alcohol detoxicification.

There is an increasing interest in alternative or herbal medicine for the prevention and treatment of various illnesses and an increasing number of scientific research is focusing on these species. As the Eleutherococcus species have wide pharmacological properties, there is a need to carry out research towards anti-leukemic properties. The abundance and variety of chemical compounds give a large hope for new drugs [10, 12-13].

The main chemical compounds present in these species are glycosides, known as eleutherosides. Eleutherosides are the derivatives of coumarins, lignans, sterols and triterpenic acids. A special attention is given to eleutherosides $\mathrm{B}, \mathrm{E}$ and E1, the compounds, which according to some authors, play a dominant role in the treatment of many diseases. Our previous phytochemical investigations have shown that eleutehrosides B, E and E1 are present in all the investigated species cultivated in Poland [1]. 
E. senticosus is the best-known species of all species belonging to Eleutherococcus genus. Its monograph can be found in several Pharmacopoeias; e.g. European, American or Polish. According to Pharmacopoeias the roots of E. senticosus should contain at least $0.08 \%$ of the sum of eleutheroside B and E. Apart from eleutherosides also polysaccharides, essential oil, eleutherans, phenolic acids and diketopiperazines have been found. The medicinal properties of E. senticosus are compared to Panax ginseng or Aralia mandshurica. This species is classified as adaptogenic plant, which can increase the ability of the organism to adapt to environmental factors and to avoid damage from such factors. It is worth noting, that the extracts from this species were used after nuclear explosion in Chernobyl in order to reduce the effects of radiation. E. senticosus is also used in the treatment of bacterial and viral infections. In addition, it has been reported, that E. senticosus has antiinflammatory, immunostimulatory and immunomodulatory properties $[1,7-9,19]$.

Apart from E. senticocus, the Chinese Traditional Medicine has also used E. gracilistylus, E. sessiliflorus and E. setchuensis. The extracts and isolated compounds have been shown to have various levels of activity such as antibacterial, antiinflammatory, anti-gout, anti-hepatitis, anti-hyperglycemic, anti-oxidant, anti-pyretic, choleretic, radioprotectant, hemostatic, immunostimulatory and hypocholesterolemic effects. The bark from the roots of E. gracilistylus described in Chinese Pharmakopoeia as Cortex Acanthopanacis (Wujiapi) is used in the treatment of rheumatism. The products containing the root bark are recommended as "therapeutic wine" $[11-12,16]$.

The anti-leukemic properties of Eleutherococcus species cultivated in Poland have not been researched yet. World literature reports mainly on one species, E. senticocus. Anti-leukemic activity of these species is unknown, in this case the main aim of studies was to establish these properties and to explain, whether they induce apoptosis or necrosis in HL60 leukemia cells.

\section{MATERIAL AND METHODS}

\section{PLANT MATERIAL}

The roots, spring and autumn leaves of E. senticosus (Rup. et Maxim.) E. setchuensis (Harms) Nakai, E. sessiliflorus (Rupr. et Maxim.) S. Y. Hu, E. gracilistylus (W. W. Smith) S. Y. Hu, E. henryi Oliv. and E. divaricatus (Siebold \& Zucc.) S. Y. Hu were obtained from arboretum in Rogów (Poland). The spring leaves were collected in June 2010, while the roots and autumn leaves in October 2010. Voucher specimens were deposited at the Chair and Department of Pharmaceutical Botany, Medical University of Lublin, Poland, and was numbered as E01, E02, E03, E04, E05, E06, respectively.

\section{PREPARATION PLANT SAMPLES}

The air-dried and powdered roots and leaves (15 g) were soaked for $24 \mathrm{~h}$ in $150 \mathrm{~mL}$ of $75 \%$ ethanol, in a round-bottomed flask. After that, the samples were sonicated in an ultrasonic bath (Polsonic, Warsaw, Poland) at room temperature for $15 \mathrm{~min}$. The liquids were carefully filtered and the plant material was re-extracted for $15 \mathrm{~min}$. with $100 \mathrm{~mL}$ of the same solvent. The filters, on which the samples were filtered, were sonicated afterwards, with $100 \mathrm{~mL} \mathrm{75 \%}$ ethanol. There was obtained $350 \mathrm{~mL}$ of each extract. The solvents were evaporated under reduced pressure at $45^{\circ} \mathrm{C}$ and subjected to lyophilisation.

\section{BIOASSAYS \\ Cell culture}

Leukemic cells (HL60 cell line, ECACC, cat. no. 98070106 ) were incubated at the concentration of $5 \times 10^{5}$ cells $/ \mathrm{mL}$ in $5 \% \mathrm{CO}_{2}$ atmosphere for $24 \mathrm{~h}$ at $37^{\circ} \mathrm{C}$. An RPMI 1640 medium (Sigma, St. Luis, USA), with 15\% fetal bovine serum (Sigma), $2 \mathrm{mM}$ L-glutamine and antibiotics [100 U/mL penicillin, $100 \mu \mathrm{M} / \mathrm{mL}$ streptomycin and 2.5 $\mu \mathrm{g} / \mathrm{mL}$ amphotericin B (Gibco, Carlsbad, USA) served as a growing medium.

\section{Cytotoxicity test-trypan blue assay}

The in vitro cytotoxicity assay was carried out using trypan blue assay. The HL60 cell line in concentration $5 \times 10^{5}$ cells $/ \mathrm{mL}$ was treated with different concentrations of testing extracts and incubated for $24 \mathrm{~h}$ at $37^{\circ} \mathrm{C}$ in air atmosphere humidified by $5 \% \mathrm{CO}_{2}$. At the end of this period, the medium was removed from each plate by aspiration. Next, the cells were washed with PBS and centrifuged at $800 \mathrm{rpm}$ for 10 min, and then PBS was removed by aspiration. Than 10 $\mu \mathrm{L}$ suspension cells were incubated for $5 \mathrm{~min}$ with the 10 $\mu l 0.4 \%$ trypan blue solution (Sigma). The samples were analyzed using an Olympus BX41 light microscope. The cells were stimulated with the ethanol extracts from the roots and leaves dissolved in DMSO at the final concentration 2; $25 ; 100 ; 300 ; 600 \mu \mathrm{g} / \mathrm{mL}$ of cell culture. The final concentration of DMSO in incubating mixture was 1\%. Every assay was performed in triplicate.

\section{Apoptotic test-Annexin $\mathrm{V}$ assay}

The annexin-V-Fluos assay was used to estimate the number of cells in the stage of apoptosis. After $24 \mathrm{~h}$ cell cultures were centrifuged at $800 \mathrm{rpm}$ for $10 \mathrm{~min}$. and the culture medium was removed. Than they were incubated for $5 \mathrm{~min}$ in the buffer comprising $10 \mathrm{mM}$ Hepes [N-(2-hydroxyethyl) piperazine-N'-(2-ethanesulfonic acid) hemisodium salt]/NaOH, pH 7.4, $140 \mathrm{mM} \mathrm{NaCl}, 2.5 \mathrm{mM}$ $\mathrm{CaCl}_{2}$, annexin $\mathrm{V}$ labeled with $0.65 \mu \mathrm{g} / \mathrm{mL}$ of FITC and propidium iodide at the concentration of $12 \mu \mathrm{g} / \mathrm{mL}$. Thereafter, the samples were analyzed by an Olympus BX41 light and fluorescence microscope for the presence of: a) viable cells-annexin $\mathrm{V}$ negative, PI negative, b) earlyapoptotic cells - annexin V positive, PI negative, c) late apoptotic/secondary necrotic-annexin $\mathrm{V}$ positive, PI positive.

The number of apoptotic cells per sample was determined as the percentage of annexine $\mathrm{V}$ positive cells per sample. HL60 cell line without the extract was used as a positive control. Cell morphology was examined using a BX41 Olympus fluorescence microscope. Data were processed according to the Multi Scan software. 


\section{RESULTS}

On the basis of the obtained results, it was concluded that all the examined extracts show cytotoxic activity against leukemic cells. The IC50 values summarized up in Table 1 are differentiated, depending on the type of raw material. The IC50 value ranged between 49 and $522 \mu \mathrm{g} / \mathrm{mL}$. The highest cytotoxicity effect was observed in the case of the extract from roots. The most active was the extract from the roots of E. divaricatus (IC50; $49 \mu \mathrm{g} / \mathrm{mL}$ ).

Table 1. IC50 [ $\mu \mathrm{g} / \mathrm{mL}]$ of extracts from Eleutherococcus spp.

\begin{tabular}{|l|c|c|c|}
\hline \multicolumn{1}{|c|}{ Species } & Roots $^{*}$ & Spring leaves $^{*}$ & Autumn leaves $^{*}$ \\
\hline E. senticosus & $\mathbf{2 0 8} \pm 0.005$ & $\mathbf{3 1 2} \pm 0.1$ & $\mathbf{2 9 9} \pm 0.004$ \\
\hline E. divaricatus & $\mathbf{4 9} \pm 0.008$ & $\mathbf{2 2 3} \pm 0.005$ & $\mathbf{2 7 0} \pm 0.005$ \\
\hline E. setchuensis & $\mathbf{1 3 5} \pm 0.06$ & $\mathbf{5 2 2} \pm 0.2$ & $\mathbf{5 1 8} \pm 0.3$ \\
\hline E. sessiliflorus & $\mathbf{1 2 8} \pm 0.009$ & $\mathbf{4 0 0} \pm 0.07$ & $\mathbf{3 2 5} \pm 0.04$ \\
\hline E. gracilistylus & $\mathbf{2 0 6} \pm 0.01$ & $\mathbf{1 0 0} \pm 0.003$ & $\mathbf{1 0 0} \pm 0.005$ \\
\hline E. henryi & $\mathbf{1 8 5} \pm 0.007$ & $\mathbf{1 1 6} \pm 0.09$ & $\mathbf{2 0 9} \pm 0.08$ \\
\hline
\end{tabular}

* Results in terms of mean \pm standard deviation

The obtained results show that IC50 values for the extracts from spring and autumn leaves are similar for the particular species. The lowest IC50 was obtained for the leaves of E. gracilistylus and E. henryi (100-209 $\mu \mathrm{g} / \mathrm{mL})$, the least active was the extract from the spring leaves of E. setchuensis $(522 \mu \mathrm{g} / \mathrm{mL})$. The percentage of living, apoptotic and necrotic leukaemic cells after $24 \mathrm{~h}$ stimulation with extracts from roots at concentration IC50 is presented in Fig. 1.

Figure 1 presents that all the samples contribute to activation of apoptosis process in leukemia cells. The number of apoptotic cells ranged between $43 \%$ and $32 \%$, necrotic cells between $17 \%$ and $9 \%$. The most apoptotic cells were determined in $E$. divaricatus $(43 \%)$ whereas the number of necrotic (toxic effect of the extracts) cells was the highest in E. gracilistylus (17\%). The percentage of apoptotic cells in controls was lower than $5 \%$.

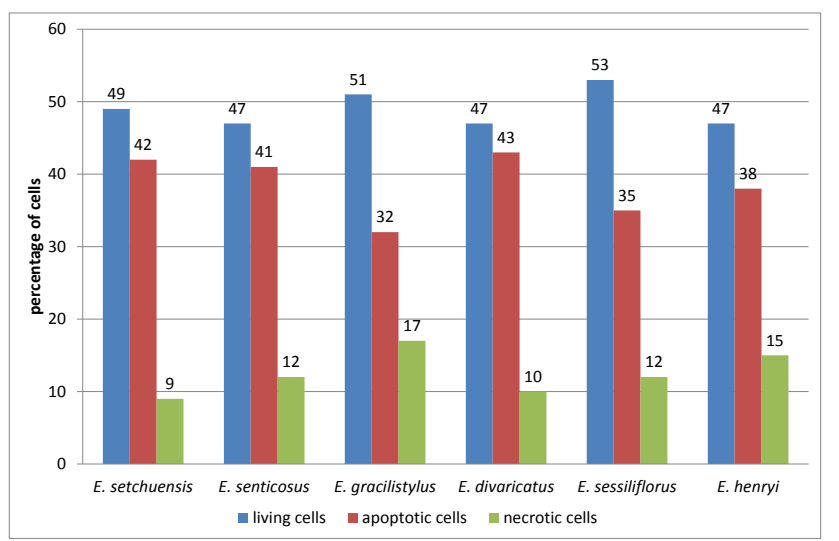

Figure 1. Living, apoptotic and necrotic HL 60 cells (24 h culture) after stimulation with ethanolic extracts from the roots of Eleutherococcus spp. The concentration of the extracts equalled IC50

\section{DISCUSSION}

Eleutherococcus spp. has been a subject of many studies for many years. Its secondary compounds have shown to have a wide range of pharmacological activities.

It is thought that eleutherosides are responsible for the medical activity of Eleutherococcus spp. Based on studies on the extracts and their ingredients, including eleutherosides, it appeared that they are very well absorbed in human intestines and accumulated in plasma, heart, kidney and liver. Unfortunately, these species are native of eastern Asia and currently are cultivated only in European botanic gardens. The chemical analysis performed by the authors has shown that the investigated species contain eleutherosides B and E, whose content is higher than the requirements of pharmacopoeia. Our earlier studies have shown that eleutherosides $\mathrm{B}, \mathrm{E}$ and $\mathrm{E} 1$ are in all roots and fruits, but not in the leaves $[1,2,17]$.

In the present study, HL-60 cell line was used as an in vitro model to examine the cytotoxic and apoptotic properties of the ethanolic extracts from the roots of spring and autumn leaves of the species belonging to Eleutherococcus genus cultivated in Poland. These species are cultivated at the botanical garden in Rogów, which lies in the Central Polish Lowlands region with geographic data such as $51^{\circ} 49^{\prime} \mathrm{N}$ and $19^{\circ} 53^{\prime} \mathrm{E}$. The vegetative period lasts for 212 days and the average annual precipitation is $596 \mathrm{~mm}$, of which $80 \%$ occurs during the vegetative period. The average annual air temperature is $7.2^{\circ} \mathrm{C}$. The average, long-term temperature is $-20.1^{\circ} \mathrm{C}$, what classified the garden to the $6 b^{\text {th }}$ sub-climate (according to "USDA Frost Hardiness Zones") and to the second zone according to the Kórnik category. These plants are grown on the acidic, luvic and sand soils [14].

Leukemia is one of the most frequently occurring diseases among young people to 30 years of age. For many years, the increase in the incidence of leukemia has been observed, especially in children and young people. Because of growing resistance to drugs, the treatment of leukemia is very difficult. New drugs with antileukemic or strengthening body properties are still being searched for. One of the most intensely studied areas of research has been the investigation of plants with anticancer action.

World scientific literature refers mainly to the research on one species, namely E. senticosus. The earlier studies performed by Hacker and Medon revealed cytotoxic effect of E. senticosus water extract against L1210 leukemia cells with ED50 value of $75 \mu \mathrm{g} / \mathrm{mL}$ [4]. Other studies performed by Yoon et al. [15] have shown anti-metastatic activity of a water extract of E. senticosus. The extract inhibited lung metastasis of colon 26-M3.1. An in vitro analysis showed that the extract affects the growth of colon 26-M3.1 cells at the concentration higher than $1000 \mu \mathrm{g} / \mathrm{mL}$ [15]. Additional studies performed by the above authors have shown that the glycoprotein fraction is responsible for the anti-metastatic activity of the extract . Based on the obtained results it appeared that the glycoproteins fraction showed higher antimetastatic activity and higher stimulation of the proliferation of splenocytes compared to the water extract [17]. In turn, the performed studies with the use of other cell lines, such 
as MOLT-4F (IC50; $14.29 \mu \mathrm{g} / \mathrm{mL})$, PC-3, HCT-15, SW-620, ACHN and A549 have showed the similar cytotoxic activity of extracts for all cell lines. The obtained IC50 values were on the level nearly $30 \mu \mathrm{g} / \mathrm{mL}$. The extracts of the E. sessiliflorus seedlings have cytotoxic action towards Calu-6 and SMU-601 cell lines. The IC50 values were $25 \mu \mathrm{g} / \mathrm{mL}$ and $196.7 \mu \mathrm{g} / \mathrm{mL}$, respectively $[2,19,6]$. Other studies showed that the water extract from the stem bark of $A$. senticosus induced apoptosis in human stomach cancer KATO III cells [4]. Unfortunately, there is still little information on the antileukemic activity of the other investigated species growing in Asia.

An important problem in the evaluation of the cytotoxic properties of extracts is to establish the way of their action. Based on the presented results, it has appeared that Eleutherococcus species cultivated in Poland possess cytotoxic properties and act via apoptosis process. The extract from the roots of $E$. divaricatus showed the highest mortality (IC50, $49 \mu \mathrm{g} / \mathrm{mL}$ ). Significantly, large differences in IC50 value between the roots and the leaves from $E$. divaricatus and E. setchuensis have been observed. During apoptosis, the morphological features of cells such as compaction and margination of nuclear chromatin, cytoplasmic condensation and membrane blebbing and cell shrinkage were observed. Taking into account the results of own studies, it appears that some species from the Polish origin have stronger cytotoxic activity than those from Asia.

The most of the studied species have a significant biological activity that is probably due to the presence of phenols, called as eleutherosides. To the best of our knowledge, neither phytochemical nor biological detailed studies have been performed for a majority of the investigated species. According to Załuski et al. these compounds are present only in the roots and fruits. Using a validated HPTLC-densitometric method, it appeared that the roots of the investigated species have high eleutherosides content $[1,16,18]$. The amount of eleutheroside B ranged between $0.5 \mathrm{mg} / \mathrm{g}$ and 3.4 $\mathrm{mg} / \mathrm{g}$; eleutheroside E between $0.5 \mathrm{mg} / \mathrm{g}$ and $1.2 \mathrm{mg} / \mathrm{g}$; and eleutheroside E1 between 0.2 and $0.9 \mathrm{mg} / \mathrm{g}$ of the sample, dry weight. The highest concentration of eleutherosides B and $\mathrm{E}$ was detected in E. henryi $(3.4 \mathrm{mg} / \mathrm{g}$ and $1.2 \mathrm{mg} / \mathrm{g}$, respectively), and of eleutheroside $\mathrm{E} 1$ in E. divaricatus (0.9 $\mathrm{mg} / \mathrm{g}$ ). According to statistical analysis, positive correlation between cytotoxic activity and eleutherosides content was not found, which could be the result of the assay conditions or the chemical structure of the eleutherosides.

These first comprehensive studies during the apoptosis process have been researched with use of the eighteen extracts from six Eleutherococcus species. There is still great interest in finding more effective and safe cancer process inhibitors, so these plants are very promising source of biologically active substances. Based on the obtained results and discussion, we can say that $E$. senticosus cultivated in Polish climatic conditions possesses strong pharmacological properties in in vitro model. To develop our research, it is necessary to isolate and identify the active compounds.

\section{CONCLUSIONS}

All these comparative studies for different parts of Eleutherococcus brought useful information on their potential use. The roots of $E$. divaricatus contain phytochemicals with the cytotoxic activity against leukemia cells. In the further research, the main attention will be focused on the isolation of single compounds and their cytotoxic activity against leukemic cells and normal human lymphocytes. Keeping in mind their rich biological properties, consumption, especially of the fresh fruits or the roots of extract products can act protectively against leukemia.

\section{ACKNOWLEDGEMENTS}

Authors are thankful to Piotr Banaszczak, director of the Botanical Garden in Rogów (Poland) for the Eleutherococcus samples.

The paper was developed using the equipment purchased within the Project ,,The equipment of innovative laboratories doing research on new medicines used in the therapy of civilization and neoplastic diseases" within the Operational Program Development of Eastern Poland 2007-2013, Priority Axis and Modern Economy, Operations 1.3 Innovation Promotion.

\section{REFERENCES}

1. Cieśla Ł. et al.: HPTLC - densitometric method for determination of eleutherosides B, E and E1 in different Eleutherococcus species. J. Chromatog. Sci., 49 (3), 182-186, 2011.

2. Feng S., Hu F., Zhao J.: Determination of eleutheroside E and eleutheroside $\mathrm{B}$ in rat plasma and tissue by high-performance liquid chromatography using solid-phase extraction and photodiode array detection. Eur. J. Pharm. Biopharm. 62, 315-320, 2006.

3. Ha E.S. et al.: Anti-metastatic activity of glycoprotein fractionated from Acanthopanax senticosus, involvement of NK-cell and macrophage activation. Arch. Pharm. Res. 27(2), 217-224, 2004.

4. Hacker B., Medon P.J.: Cytotoxic effects of Eleutherococcus senticosus aqueous extracts in combination with N6-(delta 2-isopentenyl)-adenosine and 1-beta-D-arabinofuranosylcytosine against L1210 leukemia cells. J. Pharm. Sci. 73(2), 270-272, 1984.

5. Hibasami H. et al.: Induction of apoptosis by Acanthopanax senticosus Harms and its component, sesamin in human stomach cancer KATO III cells. Oncol. Rep. 7, 1213-1216, 2000.

6. Chon S.U. et al.: Total phenolics level, antioxidant activities and cytotoxicity of young sprouts of some Traditional Korean Salad Plants. Plant. Foods Hum. Nutr., 64, 25-31, 2009.

7. Jang M.H. et al.: Protective effect of Acanthopanax senticosus against ethanol-induced apoptosis of human neuroblastoma cell line SK-N-MC. Am. J. Chin. Med. 31, 379-388, 2003.

8. Kurkin V.A. et al.: Antidepressant activity of some phytopharmaceuticals and phenylpropanoids. Pharm.Chem. J. 40 (11), 614-619, 2006.

9. Li Z.F. et al.: Two diketopiperazines from Acanthopanax senticosus Harms. J. Asian Nat. Prod. Res. 12, 51-55, 2010.

10. Liu W. (2011). Traditional herbal medicine research methods. New Jersey:John Wiley\&Sons.

11. Panossian A.: Stimulating effect of adaptogens: An overview with particular reference to their efficacy following single dose administration. Phytother. Res. 19(10), 819-838, 2005.

12. Shan B.E. et al.: Chinese medicinal herb, Acanthopanax gracilistylus, extract induces cell cycle arrest of human tumor cells in vitro. Clin. Exp. Immunol. 118, 41-8, 1999.

13. Sun Y.L., Liu L.D., Hong S.K.: Eleutherococcus senticosus as a crude medicine: Review of biological and pharmacological effects. J. Med. Plants Res., 5(25), 5946-5952, 2011.

14. Tumiłowicz J., Banaszczak P.: Drzewa i krzewy z rodziny Aquifolaceae w arboretach w Rogowie i Glinnej. Rocznik Dendrologiczny 55, 41-56, 2007. 
15. Yoon T.J. et al.: Anti-metastatic activity of Acanthopanax senticosus extract and its possible immunological mechanism of action. J. Ethnopharmacol. 93(2-3), 247-253, 2004.

16. Załuski D., Smolarz H.D., Szpilewska M.: Eleutherosides in aerial parts of Eleutherococcus species cultivated in Poland. Journal of AOAC International, 94 (5), 1422-1425, 2011.

17. Załuski D., Smolarz H.D.: Eleutherococcus senticosus - przykład rośliny adaptogennej. Post. Fit. 4, 240-246, 2008
18. Załuski D., Smolarz H.D., Gawlik-Dziki U.: Bioactive Compounds and antioxidative, antileukemic and anti-MMPs activity of Eleutherococcus species cultivated in Poland. Nat. Prod. Commun. 7(11), 1483-1486, 2012.

19. Zhao W.M. et al.: Constituents from the roots of Acanthopanax setchuenensis. Fitoterapia 70, 529-531, 1999. 